\title{
The relationship between intraoperative cerebral oximetry and postoperative delirium in patients undergoing off-pump coronary artery bypass graft surgery: a retrospective study
}

Leerang Lim', Karam Nam', Seohee Lee', Youn Joung Cho', Chan-Woo Yeom², Sanghyup Jung², Jung Yoon Moon ${ }^{2}$ and Yunseok Jeon ${ }^{1^{*}}$ (D)

\begin{abstract}
Background: Cerebral oximetry has been widely used to measure regional oxygen saturation in brain tissue, especially during cardiac surgery. Despite its popularity, there have been inconsistent results on the use of cerebral oximetry during cardiac surgery, and few studies have evaluated cerebral oximetry during off pump coronary artery bypass graft surgery (OPCAB).

Methods: To evaluate the relationship between intraoperative cerebral oximetry and postoperative delirium in patients who underwent OPCAB, we included 1439 patients who underwent OPCAB between October 2004 and December 2016 and among them, 815 patients with sufficient data on regional cerebral oxygen saturation $\left(\mathrm{rSO}_{2}\right)$ were enrolled in this study. We retrospectively analyzed perioperative variables and the reduction in $\mathrm{rSO}_{2}$ below cut-off values of $75,70,65,60,55,50,45,40$, and 35\%. Furthermore, we evaluated the relationship between the reduction in $\mathrm{rSO}_{2}$ and postoperative delirium.
\end{abstract}

Results: Delirium occurred in 105 of 815 patients. In both univariable and multivariable analyses, the duration of $\mathrm{rSO}_{2}$ reduction was significantly longer in patients with delirium at cut-offs of $<50$ and $45 \%$ (for every 5 min, adjusted odds ratio (OR) 1.007 [95\% Confidence interval (CI) 1.001 to 1.014] and adjusted OR 1.012 [1.003 to 1.021]; $p=0.024$ and 0.011 , respectively). The proportion of patients with a $\mathrm{rSO}_{2}$ reduction $<45 \%$ was significantly higher among those with delirium (adjusted OR 1.737[1.064 to 2.836], $p=0.027$ ).

Conclusions: In patients undergoing $\mathrm{OPCAB}$, intraoperative $\mathrm{rSO}_{2}$ reduction was associated with postoperative delirium. Duration of $\mathrm{rSO}_{2}$ less than $50 \%$ was $40 \%$ longer in the patients with postoperative delirium. The cut-off value of intraoperative $\mathrm{rSO}_{2}$ that associated with postoperative delirium was $50 \%$ for the total patient population and $55 \%$ for the patients younger than 68 years.

Keywords: Off-pump coronary artery bypass graft surgery, Cerebral oximetry, Delirium

\footnotetext{
* Correspondence: jeonyunseok@gmail.com

'Department of Anesthesiology and Pain Medicine, Seoul National University Hospital, 101, Daehak-ro, Jongno-gu, Seoul, Republic of Korea 03080

Full list of author information is available at the end of the article
} 


\section{Background}

Cerebral oximetry has been widely used to measure regional oxygen saturation in brain tissue continuously and non-invasively, especially during general anesthesia [1]. Using near-infrared spectroscopy (NIRS), cerebral oximetry measures regional cerebral oxygen saturation $\left(\mathrm{rSO}_{2}\right)$ by analyzing the different intensities of light at specific wavelengths transmitted and received [2,3] and monitor $\mathrm{rSO}_{2}$ underlying frontal lobes, which are vulnerable to hypoxic and hypotensive injury [4].

Because the neurological outcome is still a matter of concern in cardiac surgery, cerebral oximetry-based resuscitation during cardiac surgery has been increasingly adopted by anesthesiologists [5]. Among post-cardiac surgery neurologic complications, the reported prevalence of delirium is from $3.1 \%$ up to $52 \%$ by population and diagnostic methods, with higher prevalence in older population and aortic surgery patients, and more detection with precise cognitive function test by highly trained personnel [6-9]. Moreover, delirium is known to prolong intensive care unit and hospital stays, increase morbidity and mortality, and reduce cognitive and functional recovery [1012]. Thus, among neurologic complications, delirium is a serious and relatively common neurologic complication.

Despite the widespread use of cerebral oximetry, there have been inconsistent results regarding the relationship between the intraoperative use of cerebral oximetry and improved postoperative neurologic outcomes in cardiac surgery patients [13-17]. There have been few trials designed to identify the optimal cut-off values for cerebral oximetry, resulting in various criteria being used by different studies. Moreover, few studies on cerebral oximetry in patients undergoing off-pump coronary artery bypass graft surgery (OPCAB) have been carried out.

To evaluate the relationship between the intraoperative cerebral oximetry and postoperative delirium and identify the optimal cut-off values for intraoperative cerebral oximetry during $\mathrm{OPCAB}$, we retrospectively analyzed data of intraoperative cerebral oximetry values and postoperative delirium from patients who underwent OPCAB.

\section{Methods}

\section{Study population and anesthetic methods}

This was a retrospective single-center study approved by the Institutional Review Board of Seoul National University Hospital (IRB no. 1702-114-833). The requirement for written informed consent was waived. After IRB approval, we reviewed the electronic medical records of all patients aged over 18 years who had undergone coronary artery bypass graft surgery (CABG) between October 2004 and December 2016. Among them, we included only patients who had isolated OPCAB under general anesthesia. Patients who had been supported with perioperative intra-aortic balloon pump and/or extracorporeal membrane oxygenation were also excluded. Patients with insufficient $\mathrm{rSO}_{2}$ records less than 10 times, the -2 standard deviations (SDs) of the times of $\mathrm{rSO}_{2}$ measurement were excluded.

During the period, anesthesia for OPCAB was performed as per the institutional routine protocol at that period. When the patients entered the operating room, bi-hemispheric $\mathrm{rSO}_{2}$ was measured by NIRS from the forehead in the supine position, with other types of monitoring used for vital signs. We used INVOS Cerebral Oximeters (Medtronic, MN, USA) for $\mathrm{rSO}_{2}$ measurement. Every drug used during anesthesia was given intravenously. Patients were also monitored with a Swan-Ganz catheter (Edwards Lifesciences, Irvine, CA, USA) for mixed venous oxygen saturation $\left(\mathrm{SvO}_{2}\right)$ and cardiac index (C.I.). Patients were transferred to the cardio-pulmonary intensive care unit (ICU) after surgery being sedated and intubated.

\section{Data collection and definition}

Baseline characteristics and perioperative variables known to be related to delirium after cardiac surgery were collected [6, 9, 18-23]. These included age, sex, American Society of Anesthesiologists (ASA) classification, order of surgery, emergency, operation year, underlying diseases such as hypertension, diabetes mellitus, dyslipidemia, atrial fibrillation, history of myocardial infarction or stroke, and laboratory variables like left ventricular ejection fraction (EF), hematocrit, serum creatinine, estimated glomerular filtration rate (eGFR), serum albumin, and C-reactive protein. Postoperative outcomes, including ICU and hospital lengths of stay, acute kidney injury, new-onset atrial fibrillation, reintubation rate, and in-hospital death, were also collected.

Intraoperative variables included total anesthesia and operation times. We also used the electronic anesthetic record to extract the mean arterial pressure (MAP), $\mathrm{SvO}_{2}$, C.I., and bi-hemispheric $\mathrm{rSO}_{2}$, independently, every $5 \mathrm{~min}$. The resting MAP before anesthesia induction and initially measured $\mathrm{SvO}_{2}$ and C.I. were used as baseline values. The MAPs were recorded automatically by the anesthetic monitor, while other variables were recorded manually every 5 to $15 \mathrm{~min}$. We conducted data pre-processing on these variables according to the following steps using $R$ (R3.5.1; The $\mathrm{R}$ Foundation for Statistical Computing). First, we excluded patients who had $\mathrm{rSO}_{2}$ records that included fewer than ten measurements. Second, all data exceeding -2 SDs and +2 SDs for each variable were considered abnormally recorded and removed. Third, empty values for data recorded at 5-min intervals were substituted by the mean of the nearest two records.

After these substitutions, we calculated the total time for which the $\mathrm{rSO}_{2}$ values decreased below each cut-off $(75,70$, $65,60,55,50,45,40$, and $35 \%$ of the absolute values). We also treated the reduction in $\mathrm{rSO}_{2}$ for at least one 
measurement below each cut-off written above as a categorical variable. The same substitutions and time calculations were carried out for C.I., $\mathrm{SvO}_{2}$, and MAP, and mean values were used for receiver operating characteristic (ROC) analysis.

Postoperative delirium was determined by institutional neuropsychiatrists (C-W Yeom and colleagues) on the basis of electronic medical records. Neuropsychiatrists reviewed the doctors' records and nursing records, including the Confusion Assessment Method (CAM) for ICU (CAM-ICU) [24-26] score evaluated by the attending nurse in the ICU, consultations with neuropsychiatrists and neurologists, and prescriptions for drugs that could be used for delirium (e.g., haloperidol or quetiapine). According to Diagnostic and Statistical Manual of Mental Disorders-5 (DSM-5) [27] and Short-CAM [28] criteria, the neuropsychiatrists evaluated the signs and symptoms recorded and determined whether or not the patient had undergone postoperative delirium.

\section{Statistical analysis}

All statistical analyses were performed using SPSS, version 23.0, for Windows (IBM Corp., Armonk, NY, USA). We hypothesized a normal distribution for all variables. All categorical variables were analyzed using chi-square tests or Fisher's exact test. All continuous variables were analyzed using Student's $t$-test and logistic regression analysis. A $p$-value $<0.05$ was considered statistically significant.

First, we conducted a univariable analysis for all variables collected. A $p$-value $<0.10$ was used to select significant predictors for multivariable analysis. Next, a multivariable logistic regression analysis was performed with selected variables, and total times of $\mathrm{rSO}_{2}$ under each cut-off using a backward stepwise method. We compared the predictive ability of each prediction model to identify significant cut-offs for $\mathrm{rSO}_{2}$ related to delirium after off-pump coronary artery bypass.

\section{Results}

During the study period, 2333 patients underwent CABG. 1945 patients were undergone isolated CABG with general anesthesia. We also excluded 506 patients because of the perioperative support of IABP or ECMO, or intraoperative use of CPB. Finally, 1439 patients were included in the study. After data pre-processing, 815 patients in total were included. The flow chart for patient selection is shown in Fig. 1.

The baseline and perioperative characteristics of the patients are shown in Table 1 (no delirium group vs. delirium group, 710 [87.1\%] vs. 105 [12.9\%] patients). The delirium group had a higher average age and C-reactive protein level, and lower hematocrit, eGFR, and albumin readings, and more underlying hypertension. The group also had longer ICU and hospital stays and more frequent postoperative acute kidney injury and new onset atrial fibrillation and reintubation. In-hospital deaths numbered $3(2.9 \%)$ in the delirium group and 0 in the no delirium group, but this did not reach the level of statistical significance.

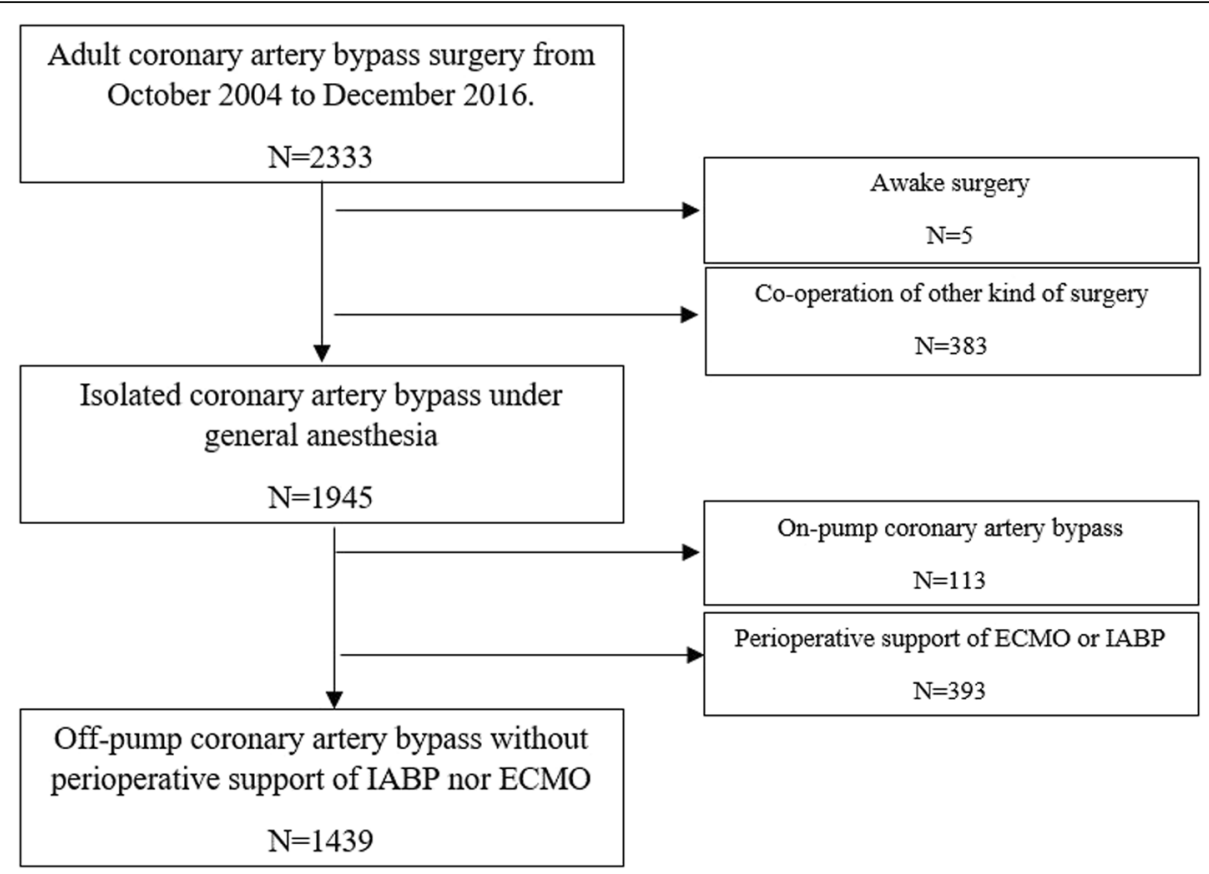

Fig. 1 Flow chart for patient selection 
Table 1 Baseline and perioperative characteristics of patients with or without delirium

\begin{tabular}{|c|c|c|c|}
\hline Characteristics & No delirium $(n=710)$ & $\operatorname{Delirium}(n=105)$ & $P$-values \\
\hline \multicolumn{4}{|l|}{ Patients characteristics } \\
\hline Age (year) & $65.2 \pm 9.6$ & $71.9 \pm 8.2$ & $<0.001$ \\
\hline Male sex & $556(78.3 \%)$ & $74(70.5 \%)$ & 0.08 \\
\hline BMI $\left(\mathrm{kg} / \mathrm{m}^{2)}\right.$ & $24.6 \pm 3.3$ & $24.1 \pm 3.1$ & 0.13 \\
\hline ASA physical status & & & 0.32 \\
\hline 1 & $19(2.7 \%)$ & $1(1.0 \%)$ & \\
\hline 2 & $200(28.2 \%)$ & $25(23.8 \%)$ & \\
\hline 3 & $478(67.3 \%)$ & $75(71.4 \%)$ & \\
\hline 4 & $13(1.8 \%)$ & $4(3.8 \%)$ & \\
\hline Hypertension & $456(64.2 \%)$ & $83(79.0 \%)$ & 0.003 \\
\hline Diabetes mellitus & 349 (49.2\%) & $57(54.3 \%)$ & 0.33 \\
\hline Dyslipidemia & $268(37.7 \%)$ & $35(33.3 \%)$ & 0.38 \\
\hline Myocardial infarction & $80(11.3 \%)$ & $15(14.3 \%)$ & 0.37 \\
\hline Atrial fibrillation & $50(7.0 \%)$ & $7(6.7 \%)$ & 0.89 \\
\hline Chronic kidney disease & $275(38.7 \%)$ & $43(41.0 \%)$ & 0.66 \\
\hline History of stroke & $452(63.7 \%)$ & $64(63.3 \%)$ & 0.59 \\
\hline Left ventricle ejection fraction (\%) & $55.1 \pm 11.1$ & $53.9 \pm 12.5$ & 0.30 \\
\hline Hematocrit (\%) & $34.8 \pm 4.0$ & $33.9 \pm 4.1$ & 0.03 \\
\hline Creatinine (mg/dL) & $1.4 \pm 1.7$ & $1.5 \pm 1.7$ & 0.3 \\
\hline Estimated GFR (ml/min/1.73m²) & $73.9 \pm 27.3$ & $63.5 \pm 26.7$ & $<0.001$ \\
\hline Albumin (g/dL) & $4.0 \pm 0.4$ & $3.8 \pm 0.4$ & $<0.001$ \\
\hline C-reactive protein (mg/dL) & $0.7 \pm 1.4$ & $1.1 \pm 2.3$ & 0.006 \\
\hline \multicolumn{4}{|l|}{ Intraoperative variables } \\
\hline Operation duration (min) & $362.2 \pm 53.4$ & $362.6 \pm 61.7$ & 0.95 \\
\hline Anesthesia duration (min) & $438.1 \pm 54.6$ & $436.1 \pm 68.2$ & 0.77 \\
\hline Re-do operation & $7(1.0 \%)$ & $1(1.0 \%)$ & 0.97 \\
\hline Emergency & $76(10.7 \%)$ & $12(11.4 \%)$ & 0.82 \\
\hline Op year & & & 0.602 \\
\hline $2005-2009$ & 54 & 6 & \\
\hline 2010-2014 & 433 & 69 & \\
\hline 2015- & 223 & 30 & \\
\hline \multicolumn{4}{|l|}{ Postoperative medical status } \\
\hline ICU lengths of stay (days) & $2.3 \pm 1.7$ & $5.8 \pm 7.1$ & $<0.001$ \\
\hline Hospital lengths of stay (days) & $9.9 \pm 7.1$ & $22.1 \pm 25.3$ & $<0.001$ \\
\hline Acute kidney injury & $133(18.7 \%)$ & $34(32.4 \%)$ & 0.001 \\
\hline New onset atrial fibrillation & $146(20.6 \%)$ & $31(29.5 \%)$ & 0.04 \\
\hline Reintubation & $27(3.8 \%)$ & $18(17.1 \%)$ & $<0.001$ \\
\hline In-hospital death & 0 & $3(2.9 \%)$ & \\
\hline
\end{tabular}

The values are expressed as mean \pm standard deviation or number (\%). ASA American Society of Anesthesiologists, BMI Body mass index, GFR Glomerular filtration rate

The duration and number of intraoperative $\mathrm{rSO}_{2}$ measurements below each cut-off are shown in Table 2. The duration of $\mathrm{rSO}_{2}$ reduction was significantly longer in patients with delirium for the cut-offs of $<50$ and $45 \%$ (for each group, mean duration (SD) of 138.7(202.7) and 64.6(141.5) vs. $100.9(159.6)$ and 39.3(100.6), $p=0.031$ and 0.027 , respectively). There was a significantly higher proportion of patients with an $\mathrm{rSO}_{2}$ reduction $<45 \%$ 
Table 2 Comparison of intraoperative $\mathrm{rSO}_{2}$ between delirium and no delirium group

\begin{tabular}{|c|c|c|c|}
\hline $\mathrm{rSO}_{2}$ & No delirium $(n=710)$ & Delirium $(n=105)$ & $P$-values \\
\hline Mean; \% & $55.5 \pm 6.8$ & $54.8 \pm 7.74$ & 0.32 \\
\hline Minimum; \% & $47.6 \pm 8.1$ & $46.7 \pm 8.33$ & 0.30 \\
\hline \multicolumn{4}{|c|}{ Mean duration of $\mathrm{rSO}_{2}$ reduction; min } \\
\hline$<75 \%$ & $451.0 \pm 141.7$ & $468.0 \pm 175.7$ & 0.27 \\
\hline$<70 \%$ & $442.0 \pm 147.9$ & $459.9 \pm 182.1$ & 0.28 \\
\hline$<65 \%$ & $402.3 \pm 167.4$ & $418.9 \pm 195.4$ & 0.36 \\
\hline$<60 \%$ & $318.2 \pm 193.4$ & $341.9 \pm 230.9$ & 0.25 \\
\hline$<55 \%$ & $204.1 \pm 196.1$ & $231.0 \pm 230.3$ & 0.20 \\
\hline$<50 \%$ & $100.9 \pm 159.6$ & $138.7 \pm 202.7$ & 0.03 \\
\hline$<45 \%$ & $39.3 \pm 100.6$ & $64.6 \pm 141.5$ & 0.03 \\
\hline$<40 \%$ & $11.7 \pm 49.2$ & $18.3 \pm 82.1$ & 0.26 \\
\hline$<35 \%$ & $4.0 \pm 28.9$ & $7.1 \pm 50.7$ & 0.38 \\
\hline \multicolumn{4}{|c|}{ Number of patients with $\mathrm{rSO}_{2}$ reduction } \\
\hline$<70 \%$ & $709(99.9 \%)$ & $105(100 \%)$ & 1 \\
\hline$<65 \%$ & 703 (99.0\%) & 104 (99.0\%) & 0.97 \\
\hline$<60 \%$ & 669 (94.2\%) & 98 (93.3\%) & 0.72 \\
\hline$<55 \%$ & $573(80.7 \%)$ & 84 (80.0\%) & 0.87 \\
\hline$<50 \%$ & 407 (57.3\%) & 69 (65.7\%) & 0.11 \\
\hline$<45 \%$ & $228(32.1 \%)$ & 44 (41.9\%) & 0.048 \\
\hline$<40 \%$ & $108(15.2 \%)$ & 17 (16.2\%) & 0.80 \\
\hline$<35 \%$ & $41(5.8 \%)$ & $6(5.7 \%)$ & 0.98 \\
\hline
\end{tabular}

The values are expressed as mean \pm standard deviation for mean, minimum $\mathrm{rSO}_{2}$ and mean duration of $\mathrm{rSO}_{2}$ reduction, number (\%) for the incidence of $\mathrm{rSO}_{2}$ reduction. $\mathrm{rSO}_{2}$ Regional cerebral oxygen saturation

among those with delirium (for each group, number of patients (\%) of $228(32.1)$ vs. $44(41.9), p=0.048)$. We also calculated number needed to treat (NNT) for the cut-off of $45 \%$. According to the Table 2 , the control event rate (CER) for delirium is $44 /(44+228)=0.16$ and the experimental event rate (EER) for delirium is $61 /(61+482)=$ 0.11 . The absolute risk reduction $(\mathrm{ARR})=\mathrm{CER}-\mathrm{EER}=$ $0.16-0.11=0.05$, therefore the NNT is $1 /(\mathrm{ARR})=1 /$ $0.05=20$. That is, 20 patients need to be treated to reduce 1 episode of delirium.

Intraoperative hemodynamic variables are shown in Supplementary Table 1 in Additional file 1 . Based on the results of an ROC analysis for the mean values of each variable, the cut-off was determined as $68 \mathrm{mmHg}, \quad 2.2 \mathrm{~L} / \mathrm{min} / \mathrm{m}^{2}$, and $64 \%$ for MAP, C.I., and $\mathrm{SvO}_{2}$, respectively. The total durations of reduction below the cut-off and minimum values were calculated. For all three variables, the total duration of reduction below each cut-off was significantly longer in the delirium group than the no delirium group $(p=0.001)$, and these cut-off values were selected for a multivariable analysis as categorical variables.
The odds ratio (OR), 95\% confidence interval (CI), and $p$-values of $\mathrm{rSO}_{2}$ for each cut-off are shown in Table 3. The OR and $95 \% \mathrm{CI}$ were calculated for every $5 \mathrm{~min}$ of $\mathrm{rSO}_{2}$ reduction below each cut-off value. Age, sex, hypertension, preoperative hematocrit, eGFR, serum albumin and C-reactive protein level, intraoperative MAP, C.I. and $\mathrm{SvO}_{2}$ reduction below each cut-off of $\mathrm{ROC}$ analysis were considered as covariables. There was no multicollinearity between the variables included in the analysis, especially between the intraoperative hemodynamic variables and $\mathrm{rSO}_{2}$ for the occurrence of postoperative delirium. Multivariable logistic regression analysis revealed that the duration of $\mathrm{rSO}_{2}$ below the 50 and $45 \%$ cut-offs was significantly associated with postoperative delirium (for every 5 min, adjusted OR 1.007 [95\% CI 1.001-1.014] and 1.012 [1.003-1.021]; $p=0.024$ and 0.011 , respectively). Each model showed good fitness (Hosmer-Lemeshow's goodness-of-fit: $p=0.729$ and 0.962 , respectively). The $\mathrm{rSO}_{2}$ values below $45 \%$ for at least one measurement were significantly associated with postoperative delirium, and the model fitness was good (adjusted OR 1.737, $p=$ 0.027; Hosmer-Lemeshow's goodness-of-fit: $p=0.923$; Table 4). According to the analysis of variance between the two group for the duration of $\mathrm{rSO}_{2}$ reduction $<45 \%$ or $50 \%$, and delirium, the $p$-values of linearity were $<0.05$ and the $p$-values of deviation from linearity were $>0.05$, indicating that there is a linear relationship between the duration of $\mathrm{rSO}_{2}$ reduction below $45 \%$ or $50 \%$ and the probability of postoperative delirium. The duration of $\mathrm{rSO}_{2}$ below 50 and $45 \%$ was also associated with postoperative acute kidney injury, a longer ICU stay, and longer hospital stay (Supplementary Table 2 in Additional file 1).

A post hoc power analysis was performed for the occurrence of $\mathrm{rSO} 2$ reduction $<45 \%$ with chi-squared test based on the result described in Table 2 . The analysis revealed a power of this study above 0.95 for the occurrence of $\mathrm{rSO} 2$ reduction $<45 \%$.

Based on the ROC analysis, the cut-off age for postoperative delirium occurrence was 68 . We conducted a subgroup analysis based on this cut-off. Among 815 patients, 398 (48.8\%) were under age 68, and delirium occurred in 19 patients (4.8\%). Baseline and perioperative characteristics, including intraoperative hemodynamic variables, are shown in Supplementary Table 3 in Additional file 1. Based on a univariable analysis, preoperative $\mathrm{EF}$, and albumin and Creactive protein levels were selected for a multivariable analysis. Supplementary Table 4 Additional file 1 shows the duration and number of intraoperative $\mathrm{rSO}_{2}$ values below each cut-off in patients under 68 years of age. The mean and minimum $\mathrm{rSO}_{2}$ values were significantly lower in the delirium group. The duration of $\mathrm{rSO}_{2}$ reduction was significantly longer in patients with delirium for the cut-offs of $<55,50$, and $45 \%$, and the proportion of patients with an $\mathrm{rSO}_{2}$ reduction below 50 and $45 \%$ was significantly higher among those 
Table 3 Unadjusted and adjusted odds ratios of intraoperative reduction of $\mathrm{rSO}_{2}$ of each cut-offs for postoperative delirium

\begin{tabular}{|c|c|c|c|c|}
\hline Intraoperative $\mathrm{rSO}_{2}$ & $\begin{array}{l}\text { Unadjusted OR } \\
(95 \% \mathrm{Cl})\end{array}$ & $P$-values & $\begin{array}{l}\text { Adjusted OR } \\
(95 \% \mathrm{Cl})\end{array}$ & $P$-values \\
\hline Mean & 0.985 (0.957 to 1.014$)$ & 0.32 & 0.976 (0.942 to 1.011$)$ & 0.18 \\
\hline Minimum & 0.987 (0.962 to 1.012 ) & 0.30 & 0.977 (0.948 to 1.006$)$ & 0.12 \\
\hline \multicolumn{5}{|c|}{ Duration of $\mathrm{rSO}_{2}$ reduction (for every $5 \mathrm{~min}$ ) } \\
\hline$<75 \%$ & 1.004 (0.997 to 1.010$)$ & 0.27 & 1.006 (0.999 to 1.013$)$ & 0.12 \\
\hline$<70 \%$ & 1.004 (0.997 to 1.010$)$ & 0.28 & 1.005 (0.998 to 1.012$)$ & 0.14 \\
\hline$<65 \%$ & 1.003 (0.997 to 1.009 ) & 0.36 & 1.004 (0.997 to 1.011$)$ & 0.24 \\
\hline$<60 \%$ & 1.003 (0.998 to 1.008$)$ & 0.25 & 1.004 (0.998 to 1.010$)$ & 0.16 \\
\hline$<55 \%$ & 1.003 (0.998 to 1.008 ) & 0.20 & 1.004 (0.999 to 0.010$)$ & 0.15 \\
\hline$<50 \%$ & 1.006 (1.001 to 1.011$)$ & 0.03 & 1.007 (1.001 to 1.014$)$ & 0.02 \\
\hline$<45 \%$ & 1.009 (1.001 to 1.017$)$ & 0.03 & $1.012(1.003$ to 1.021$)$ & 0.01 \\
\hline$<40 \%$ & 1.009 (0.994 to 1.025$)$ & 0.26 & 1.013 (0.995 to 1.030$)$ & 0.15 \\
\hline$<35 \%$ & 1.011 (0.986 to 1.037 ) & 0.38 & 1.021 (0.990 to 1.053$)$ & 0.19 \\
\hline \multicolumn{5}{|c|}{ Occurrence of $\mathrm{rSO}_{2}$ reduction } \\
\hline$<70 \%$ & . & 1 & & 1 \\
\hline$<65 \%$ & 1.036 (0.126 to 8.502$)$ & 0.97 & . & 1 \\
\hline$<60 \%$ & 0.858 (0.374 to 1.966$)$ & 0.72 & 1.460 (0.423 to 5.044$)$ & 0.55 \\
\hline$<55 \%$ & 0.956 (0.572 to 1.598$)$ & 0.87 & 0.935 (0.492 to 1.777$)$ & 0.84 \\
\hline$<50 \%$ & 1.427 (0.929 to 2.192) & 0.11 & 1.599 (0.965 to 2.649) & 0.07 \\
\hline$<45 \%$ & 1.525 (1.003 to 2.317$)$ & 0.048 & 1.737 (1.064 to 2.836$)$ & 0.03 \\
\hline$<40 \%$ & 1.077 (0.616 to 1.882 ) & 0.80 & 1.236 (0.657 to 2.326$)$ & 0.51 \\
\hline$<35 \%$ & 0.989 (0.409 to 2.390$)$ & 0.98 & 0.839 (0.306 to 2.299$)$ & 0.73 \\
\hline
\end{tabular}

$\mathrm{rSO}_{2}$ Regional cerebral oxygen saturation, $\mathrm{OR}$ Odds ratio, $\mathrm{Cl}$ Confidence interval

Table 4 Odds ratios of predictors for postoperative delirium

\begin{tabular}{|c|c|c|}
\hline Variables & $\begin{array}{l}\text { Multivariable logistic regression } \\
\text { - OR }(95 \% \mathrm{Cl})\end{array}$ & $\begin{array}{l}\text { Univariable logistic regression } \\
\text { - OR }(95 \% \mathrm{Cl})\end{array}$ \\
\hline Age (year) & $1.093(1.058$ to 1.129$)$ & $1.097(1.066$ to 1.128$)$ \\
\hline Sex (Female) & - & 1.512 (0.959 to 2.386$)$ \\
\hline \multicolumn{3}{|l|}{ Preoperative } \\
\hline Hypertension & $1.908(1.062$ to 3.428$)$ & $2.101(1.282$ to 3.445$)$ \\
\hline Hematocrit (\%) & - & 0.943 (0.896 to 0.993$)$ \\
\hline estimated GFR ( $\left.\mathrm{ml} / \mathrm{min}^{\prime} 1.73 \mathrm{~m}^{2}\right)$ & - & 0.987 (0.980 to 0.994$)$ \\
\hline Albumin (g/dL) & 0.485 (0.276 to 0.852$)$ & 0.384 (0.244 to 0.605$)$ \\
\hline C-reactive protein (mg/dL) & - & $1.163(1.044$ to 1.295$)$ \\
\hline \multicolumn{3}{|l|}{ Intraoperative } \\
\hline $\mathrm{MAP}<68 \mathrm{mmHg}$ & - & $1.002(1.001$ to 1.004$)$ \\
\hline C.I. $<2.2 \mathrm{~L} / \mathrm{min}^{\prime} \mathrm{m}^{2}$ & - & $1.002(1.001$ to 1.003$)$ \\
\hline $\mathrm{SvO}_{2}<64 \%$ & - & $1.003(1.001$ to 1.005$)$ \\
\hline Occurrence of $\mathrm{rSO}_{2}<45 \%$ & 1.737 (1.064 to 2.836$)$ & $1.525(1.003$ to 2.317$)$ \\
\hline
\end{tabular}

OR Odds ratio, $\mathrm{Cl}$ Confidence interval, GFR Glomerular filtration rate, MAP Mean arterial pressure, C.I. Cardiac index, $\mathrm{SvO}_{2}$ Mixed venous oxygen saturation, $r \mathrm{SO}_{2}$ Regional cerebral oxygen saturation 
with delirium. These cut-offs were higher than those of the overall group in Table 2. In the multivariable logistic regression analysis, the duration of $\mathrm{rSO}_{2}$ lower than 55,50 , and $45 \%$ was significantly associated with postoperative delirium (for every $5 \mathrm{~min}$, adjusted OR 1.012, 1.015, and 1.015, $p=$ $0.035,0.006$, and 0.024 , respectively), as shown in Table 5 . However, the model fitness for the cut-off of $55 \%$ was not good (Hosmer-Lemeshow's goodness-of-fit: $p=0.022$ ), whereas those for the other cut-offs were good. The area under receiver operating characteristic (AUROC) for prediction models for patients under 68 years of age are shown in Additional file 2. The AUROC for the model without $\mathrm{rSO}_{2}$ was 0.688 (95\% CI $0.565-0.816, p=0.007)$, and improved with $\mathrm{rSO}_{2}$ measurement, up to 0.752 (95\% CI $0.640-0.865$, $p<0.001$ ) with the duration of $\mathrm{rSO}_{2}<50 \%$.

Among 417 patients over 68 years of age, the incidence of delirium was $20.6 \%(86 / 417)$. In the univariable analysis, older age, hypertension, and low preoperative eGFR were significantly associated with postoperative delirium in the old age group. However, there was no significant association between intraoperative reduction in $\mathrm{rSO}_{2}$ and postoperative delirium for all cut-offs in either the univariable or the multivariable logistic regression analysis.

\section{Discussion}

The results of this study suggest that decreases in intraoperative $\mathrm{rSO}_{2}$ below $50 \%$ are associated with postoperative delirium after OPCAB. This was also associated with postoperative acute kidney injury and longer ICU and hospital stays. Among patients less than 68 years of age, $\mathrm{rSO}_{2}$ lower than $55 \%$ was associated with postoperative delirium. However, in patients more than 68 years old, intraoperative $\mathrm{rSO}_{2}$ was not associated with postoperative delirium.

The incidence of delirium in this study was $12.9 \%$, slightly lower than reported by previous studies using similar diagnostic methods (23 to 52\%) [9]. One of the reasons for this difference may be the age of the included patients, half of whom were under 68 years of age. Conversely, previous studies have included mostly patients over 60 years of age [9]. Age is one of the most powerful risk factors for delirium after cardiac surgery [29]. Furthermore, we selected only patients who had underwent $\mathrm{OPCAB}$, while in previous studies both onpump and off-pump cardiac surgery were included, with on-pump surgery being more common $[9,18,19,29]$. Although the topic remains controversial, some studies have suggested that beating heart surgery can lower the risk of delirium caused by solid microemboli or the

Table 5 Odds ratios of intraoperative reduction of $\mathrm{rSO}_{2}$ of each cut-offs for postoperative delirium in patients under age 68

\begin{tabular}{|c|c|c|c|c|}
\hline Intraoperative $\mathrm{rSO}_{2}$ & Unadjusted OR (95\% Cl) & $P$-values & Adjusted OR (95\% Cl) & $P$-values \\
\hline Mean & 0.920 (0.869 to 0.975$)$ & 0.004 & 0.927 (0.874 to 0.984$)$ & 0.01 \\
\hline Minimum & 0.934 (0.886 to 0.984$)$ & 0.01 & 0.940 (0.891 to 0.992$)$ & 0.03 \\
\hline \multicolumn{5}{|c|}{ Duration of $\mathrm{rSO}_{2}$ reduction (for every $5 \mathrm{~min}$ ) } \\
\hline$<75 \%$ & 0.999 (0.982 to 1.016$)$ & 0.87 & 0.997 (0.979 to 1.016$)$ & 0.78 \\
\hline$<70 \%$ & 1.001 (0.985 to 1.016$)$ & 0.95 & 0.999 (0.982 to 1.016$)$ & 0.89 \\
\hline$<65 \%$ & 1.005 (0.992 to 1.018$)$ & 0.48 & 1.003 (0.988 to 1.017 ) & 0.73 \\
\hline$<60 \%$ & 1.008 (0.997 to 1.019$)$ & 0.16 & 1.005 (0.993 to 1.018$)$ & 0.36 \\
\hline$<55 \%$ & 1.011 (1.001 to 1.022$)$ & 0.03 & $1.012(1.001$ to 1.022$)$ & 0.04 \\
\hline$<50 \%$ & 1.015 (1.005 to 1.025$)$ & 0.004 & 1.015 (1.004 to 1.025$)$ & 0.006 \\
\hline$<45 \%$ & 1.016 (1.003 to 1.029$)$ & 0.02 & 1.015 (1.002 to 1.029$)$ & 0.02 \\
\hline$<40 \%$ & 1.014 (0.987 to 1.042 ) & 0.3 & 1.010 (0.982 to 1.039$)$ & 0.49 \\
\hline$<35 \%$ & 1.017 (0.980 to 1.057) & 0.37 & 1.011 (0.972 to 1.052 ) & 0.59 \\
\hline \multicolumn{5}{|c|}{ Occurrence of $\mathrm{rSO}_{2}$ reduction } \\
\hline$<75 \%$ & . & 1 & . & 1 \\
\hline$<70 \%$ & . & 1 & . & 1 \\
\hline$<65 \%$ & . & 1 & . & 1 \\
\hline$<60 \%$ & . & 1 & . & 1 \\
\hline$<55 \%$ & 4.970 (0.654 to 37.782$)$ & 0.12 & 4.231 (0.551 to 32.480$)$ & 0.17 \\
\hline$<50 \%$ & 4.156 (1.191 to 14.503$)$ & 0.03 & 4.013 (1.112 to 14.482$)$ & 0.03 \\
\hline$<45 \%$ & 2.634 (1.034 to 6.709) & 0.04 & 2.283 (0.906 to 6.266$)$ & 0.08 \\
\hline$<40 \%$ & $2.662(0.971$ to 7.295$)$ & 0.06 & $2.757(0.980$ to 7.757$)$ & 0.06 \\
\hline$<35 \%$ & $1.114(0.141$ to 8.817$)$ & 0.92 & $0.989(0.118$ to 8.300$)$ & 0.99 \\
\hline
\end{tabular}


alteration of cerebral autoregulation during the cardiopulmonary bypass $(\mathrm{CPB})$ period $[18,23,30]$.

Considering the cut-off values for intraoperative $\mathrm{rSO}_{2}$ during cardiac surgery, Yao and colleagues [17] set multiple thresholds indicating different degrees of hypoxic brain injury. They used 50, 45, 40, 35, and 30\% as absolute values, corresponding to the baseline value minus 1 , 1.5, 2, 2.5, and 3 SDs. $\mathrm{A} \mathrm{rSO}_{2}$ reduction below $40 \%$ was significantly associated with postoperative neurologic dysfunction after cardiac surgery with $\mathrm{CPB}$ based on a multivariable analysis. In several studies, including randomized controlled trials, prolonged cerebral desaturation below $50 \%$ as an absolute value or more than $20 \%$ of baseline was associated with postoperative cognitive decline [31-34]. However, these studies were mostly conducted on cardiac surgery with $\mathrm{CPB}$ and evaluated only one or two thresholds rather than various cut-off ranges.

We aimed to determine whether there is a certain cutoff value for intraoperative $\mathrm{rSO}_{2}$ during OPCAB associated with increased postoperative delirium. Previously, it has been shown that $\mathrm{rSO}_{2}$ values measured by cerebral oximetry reflect a balance between oxygen consumption and supply in the frontal lobe, especially in the "watershed" area in the junction between the anterior and middle cerebral arteries $[3,16]$. Intraoperative cerebral hypoperfusion is also known to be related to postoperative neurological dysfunction after cardiac surgery [17, 30-32]. However, several randomized controlled trials showed inconsistent results regarding the relationship between intraoperative $\mathrm{rSO}_{2}$ reductions during cardiac surgery and postoperative neurologic outcomes. Two meta-analyses focusing on the use of cerebral oximetry and postoperative outcomes after cardiac surgery concluded that there was a low level of evidence linking intraoperative reductions in $\mathrm{rSO}_{2}$ with postoperative neurologic outcomes $[13,35]$.

There may be several reasons for the inconsistent results regarding the usefulness of cerebral oximetry during cardiac surgery. First, heterogeneous patients were enrolled in previous studies. These studies involved various types of cardiovascular surgeries, including valvar surgery, coronary artery bypass surgery, cardiac tumor surgery, and aortic surgery, which involve different applications of intraoperative $\mathrm{CPB}$ and hypothermia. Transient but significant dysfunction in cerebral autoregulation and cerebral desaturation due to hemodilution or microemboli may occur with $\mathrm{CPB}$. Cerebral oxygen consumption is also altered during $\mathrm{CPB}$ and hypothermia $[14,15,17,18,36,37]$. Thus, with or without $\mathrm{CPB}$, these heterogeneous populations may have led to inconsistent results. In the current study, to increase the homogeneity of patients, we included only patients who had undergone $\mathrm{OPCAB}$ without $\mathrm{CPB}$.

In addition, previous studies including several randomized controlled trials, used various protocols and $\mathrm{rSO}_{2}$ cut-off values to trigger intervention to restore $\mathrm{rSO}_{2}$. This may also have contributed to the inconsistent results. Conversely, we evaluated the relationship between $\mathrm{rSO}_{2}$ reductions and postoperative delirium at various cut-off values. By analyzing not only the occurrence but also the total duration of $\mathrm{rSO}_{2}$ reduction, we aimed to identify the threshold of hypoxia exceeding the compensating capacity of the brain relating to the duration of cerebral desaturation.

We also included intraoperative MAP, C.I., and $\mathrm{SvO}_{2}$ as risk factors for postoperative delirium occurrence. Although these hemodynamic variables can affect intraoperative cerebral perfusion and consequently postoperative delirium, they have not been included in many previous studies. In our study, by conducting a regression analysis, we attempted to rule out the possibility of multicollinearity between these hemodynamic variables and $\mathrm{rSO}_{2}$.

In the subgroup analysis of patients under age 68 , only preoperative EF, level of albumin, and C-reactive protein were associated with postoperative delirium by univariable analysis. The cut-off value of $\mathrm{rSO}_{2}$ associated with postoperative delirium was $55 \%$, which was slightly higher than the $50 \%$ cut-off for the entire study group. Moreover, in patients over age $68, \mathrm{rSO}_{2}$ was not associated with postoperative delirium. The pathophysiology of postoperative delirium is complex, and age is one of the most powerful risk factors, along with history of hypertension $[6,9,19,21]$. Thus, in old patients, other factors associated with old age may more strongly influence the occurrence of postoperative delirium than intraoperative brain oxygenation.

This study has several limitations. First, because this study was retrospective in nature, risk factors that could affect postoperative delirium could not be perfectly controlled. Similarly, the anesthetic management to maintain or restore $\mathrm{rSO}_{2}$ was not controlled. Second, this study involved cardiac surgery cases from 2004 to 2016, and surgical and anesthetic methods and techniques evolved over this period. These changes may have influenced the occurrence of postoperative delirium. Third, preoperative neurologic function was not assessed, and postoperative delirium was estimated using medical records and prescription history. The incidence of postoperative delirium may therefore have been underestimated. Finally, we could not assess the baseline $\mathrm{rSO}_{2}$ values. Previous studies consistently found that preoperative baseline $\mathrm{rSO}_{2}$ was associated with postoperative delirium in cardiac surgery $[13,15,35]$. However, since this was a retrospective study we could not access or identify the baseline $\mathrm{rSO}_{2}$ before anesthesia induction or at the beginning of the surgery, and also the impact of baseline $\mathrm{rSO}_{2}$ on postoperative delirium could not be evaluated. Consequently, the decrease in $\mathrm{rSO}_{2}$ relative to the baseline was not estimated. The differences between the patients who were with low baseline and lesser reduction of $\mathrm{rSO}_{2}$ and with high baseline and more 
reduction of $\mathrm{rSO}_{2}$, could not be evaluated. We suggested that the baseline value itself may not be in normal physiologic values for cardiac surgery patients and the reserves from the baseline values may be different by the individuals. We based our hypothesis on our clinical experience, and thus we considered absolute cut-offs to be of more clinical significance. Considering the limitations of this study, prospective, randomized controlled studies may be needed to evaluate the effect of intervention to maintain $\mathrm{rSO}_{2}$ over $50 \%$ (or $55 \%$ for patients under 68 years of age) during OPCAB.

\section{Conclusions}

In patients undergoing $\mathrm{OPCAB}$, intraoperative $\mathrm{rSO}_{2}$ below $50 \%$ was associated with postoperative delirium. Among patients younger than 68 years old, $\mathrm{rSO}_{2}$ below $55 \%$ was associated with postoperative delirium. Therefore, $\mathrm{rSO}_{2}$ should be maintained at over $50 \%$, or over $55 \%$ among patients less than 68 years old, during $\mathrm{OPCAB}$.

\section{Supplementary information}

Supplementary information accompanies this paper at https://doi.org/10 1186/s12871-020-01180-x.

Additional file 1 revised.docx Supplementary tables.

Additional file 2 JPG Supplementary Fig. 1 The ROC curves of multivariable prediction model for patients under age 68

\section{Abbreviations}

NIRS: Near-infrared spectroscopy; $\mathrm{rSO}_{2}$ : Regional cerebral oxygen saturation; OPCAB: Off pump coronary artery bypass graft surgery; CABG: Coronary artery bypass graft surgery; SD: Standard deviation; $\mathrm{SvO}_{2}$ : Mixed venous oxygen saturation; C.I.: Cardiac index; ICU: Intensive care unit; EF: Ejection fraction; eGFR: Estimated glomerular filtration rate; MAP: Mean arterial pressure; ROC: Receiver operating characteristic; CAM: Confusion assessment method; DSM-5: Diagnostic and statistical manual of mental disorders-5; ASA: American society of anesthesiologists; OR: Odds ratio; Cl: Confidence interval; AUROC: Area under receiver operating characteristic;

CPB: Cardiopulmonary bypass

\section{Acknowledgements}

Statistical analysis has been checked by Institutional Medical Research Collaborating Center.

\section{Authors' contributions}

$\mathrm{LL}$ and $Y J$ conceptualized and designed the study, LL, KN, SL,YJC contributed to the acquisition of data. LL, KN and YJ contributed to the analysis, interpretation of data and C-WY,SHJ, and JYM have made to contribution to the analysis of data and determination for postoperative delirium. LL have drafted the initial work and all authors substantively revised it. All authors read and approved the final manuscript.

\section{Funding}

None declared.

\section{Availability of data and materials}

The datasets used and/or analyzed during the current study are available from the corresponding author on reasonable request.

\section{Ethics approval and consent to participate}

This study was approved by the Institutional Review Board of Seoul National University Hospital (IRB no. 1702-114-833) and the need for written informed consent was waived.
Consent for publication

Not applicable.

\section{Competing interests}

The authors declare that they have no competing interests.

\section{Author details}

${ }^{1}$ Department of Anesthesiology and Pain Medicine, Seoul National University Hospital, 101, Daehak-ro, Jongno-gu, Seoul, Republic of Korea 03080.

${ }^{2}$ Department of Neuropsychiatry, Seoul National University Hospital, 101,

Daehak-ro, Jongno-gu, Seoul, Republic of Korea 03080.

Received: 26 July 2020 Accepted: 1 October 2020

Published online: 14 November 2020

References

1. Jobsis FF. Noninvasive, infrared monitoring of cerebral and myocardial oxygen sufficiency and circulatory parameters. Science. 1977;198(4323):1264-7.

2. Tosh W, Patteril M. Cerebral oximetry. BJA Educ. 2016;16(12):417-21.

3. Murkin JM, Arango M. Near-infrared spectroscopy as an index of brain and tissue oxygenation. Br J Anaesth. 2009;103(Suppl 1):i3-13.

4. Payabvash S, Souza LC, Wang Y, Schaefer PW, Furie KL, Halpern EF, et al. Regional ischemic vulnerability of the brain to hypoperfusion: the need for location specific computed tomography perfusion thresholds in acute stroke patients. Stroke. 2011;42(5):1255-60.

5. Vretzakis G, Georgopoulou S, Stamoulis K, Stamatiou G, Tsakiridis K, Zarogoulidis $\mathrm{P}$, et al. Cerebral oximetry in cardiac anesthesia. J Thorac Dis. 2014;6(Suppl 1):S60-9.

6. Koster S, Oosterveld FG, Hensens AG, Wijma A, van der Palen J. Delirium after cardiac surgery and predictive validity of a risk checklist. Ann Thorac Surg. 2008;86(6):1883-7.

7. Plaschke K, Fichtenkamm P, Schramm C, Hauth S, Martin E, Verch M, et al. Early postoperative delirium after open-heart cardiac surgery is associated with decreased bispectral EEG and increased cortisol and interleukin-6. Intensive Care Med. 2010:36(12):2081-9.

8. Kazmierski J, Kowman M, Banach M, Fendler W, Okonski P, Banys A, et al. Incidence and predictors of delirium after cardiac surgery: results from the IPDACS study. J Psychosom Res. 2010;69(2):179-85.

9. Koster S, Hensens AG, Schuurmans MJ, van der Palen J. Risk factors of delirium after cardiac surgery: a systematic review. Eur J Cardiovasc Nurs. 2011;10(4):197-204.

10. Jackson JC, Gordon SM, Hart RP, Hopkins RO, Ely EW. The association between delirium and cognitive decline: a review of the empirical literature. Neuropsychol Rev. 2004;14(2):87-98.

11. Ely EW, Shintani A, Truman B, Speroff T, Gordon SM, Harrell FE Jr, et al. Delirium as a predictor of mortality in mechanically ventilated patients in the intensive care unit. JAMA. 2004;291(14):1753-62.

12. McKhann GM, Grega MA, Borowicz LM Jr, Bechamps M, Selnes OA, Baumgartner WA, et al. Encephalopathy and stroke after coronary artery bypass grafting: incidence, consequences, and prediction. Arch Neurol. 2002;59(9):1422-8.

13. Zheng F, Sheinberg R, Yee MS, Ono M, Zheng Y, Hogue CW. Cerebral nearinfrared spectroscopy monitoring and neurologic outcomes in adult cardiac surgery patients: a systematic review. Anesth Analg. 2013;116(3):663-76.

14. Lei L, Katznelson R, Fedorko L, Carroll J, Poonawala H, Machina M, et al. Cerebral oximetry and postoperative delirium after cardiac surgery: a randomised, controlled trial. Anaesthesia. 2017:72(12):1456-66.

15. Schoen J, Meyerrose J, Paarmann H, Heringlake M, Hueppe M, Berger KU. Preoperative regional cerebral oxygen saturation is a predictor of postoperative delirium in on-pump cardiac surgery patients: a prospective observational trial. Crit Care. 2011:15(5):R218.

16. Green DW, Kunst G. Cerebral oximetry and its role in adult cardiac, noncardiac surgery and resuscitation from cardiac arrest. Anaesthesia. 2017; 72(Suppl 1):48-57.

17. Yao FS, Tseng CC, Ho CY, Levin SK, Illner P. Cerebral oxygen desaturation is associated with early postoperative neuropsychological dysfunction in patients undergoing cardiac surgery. J Cardiothorac Vasc Anesth. 2004;18(5): 552-8.

18. Bucerius J, Gummert JF, Borger MA, Walther T, Doll N, Falk V, et al. Predictors of delirium after cardiac surgery delirium: effect of beating-heart (off-pump) surgery. J Thorac Cardiovasc Surg. 2004;127(1):57-64. 
19. Guenther U, Theuerkauf N, Frommann I, Brimmers K, Malik R, Stori S, et al. Predisposing and precipitating factors of delirium after cardiac surgery: a prospective observational cohort study. Ann Surg. 2013;257(6):1160-7.

20. Kazmierski J, Kowman M, Banach M, Pawelczyk T, Okonski P, Iwaszkiewicz A, et al. Preoperative predictors of delirium after cardiac surgery: a preliminary study. Gen Hosp Psychiatry. 2006:28(6):536-8.

21. Miyazaki S, Yoshitani K, Miura N, Irie T, Inatomi Y, Ohnishi Y, et al. Risk factors of stroke and delirium after off-pump coronary artery bypass surgery. Interact Cardiovasc Thorac Surg. 2011;12(3):379-83.

22. Otomo S, Maekawa K, Goto T, Baba T, Yoshitake A. Pre-existing cerebral infarcts as a risk factor for delirium after coronary artery bypass graft surgery. Interact Cardiovasc Thorac Surg. 2013;17(5):799-804.

23. Sockalingam S, Parekh N, Bogoch II, Sun J, Mahtani R, Beach C, et al. Delirium in the postoperative cardiac patient: a review. J Card Surg. 2005; 20(6):560-7.

24. Ely EW, Inouye SK, Bernard GR, Gordon S, Francis J, May L, et al. Delirium in mechanically ventilated patients: validity and reliability of the confusion assessment method for the intensive care unit (CAM-ICU). JAMA. 2001; 286(21):2703-10.

25. Ely EW, Margolin R, Francis J, May L, Truman B, Dittus R, et al. Evaluation of delirium in critically ill patients: validation of the confusion assessment method for the intensive care unit (CAM-ICU). Crit Care Med. 2001;29(7): 1370-9.

26. Heo EY, Lee BJ, Hahm BJ, Song EH, Lee HA, Yoo CG, et al. Translation and validation of the Korean confusion assessment method for the intensive care unit. BMC Psychiatry. 2011;11:94.

27. Sachdev PS, Blacker D, Blazer DG, Ganguli M, Jeste DV, Paulsen JS, et al. Classifying neurocognitive disorders: the DSM-5 approach. Nat Rev Neurol. 2014;10(11):634-42.

28. Inouye SK. The short confusion assessment method (short CAM): training manual and coding guide. Boston: Hospital Elder Life Program; 2014. https://www.hospitalelderlifeprogram.org/uploads/disclaimers/Short_CAM_ Training_Manual_10-9-14.pdf. Accessed 30 Nov 2019.

29. Banach M, Kazmierski J, Kowman M, Okonski PK, Sobow T, Kloszewska I, et al. Atrial fibrillation as a nonpsychiatric predictor of delirium after cardiac surgery: a pilot study. Med Sci Monit. 2008;14(5):CR286-91.

30. Gottesman RF, Grega MA, Bailey MM, Pham LD, Zeger SL, Baumgartner WA, et al. Delirium after coronary artery bypass graft surgery and late mortality. Ann Neurol. 2010;67(3):338-44.

31. Colak Z, Borojevic M, Bogovic A, Ivancan V, Biocina B, Majeric-Kogler V. Influence of intraoperative cerebral oximetry monitoring on neurocognitive function after coronary artery bypass surgery: a randomized, prospective study. Eur J Cardiothorac Surg. 2015;47(3):447-54.

32. Slater JP, Guarino T, Stack J, et al. Cerebral oxygen desaturation predicts cognitive decline and longer hospital stay after cardiac surgery. Ann Thorac Surg. 2009;87(1):36-45

33. Rogers CA, Stoica S, Ellis L, Stokes EA, Wordsworth S, Dabner L, et al. Randomized trial of near-infrared spectroscopy for personalized optimization of cerebral tissue oxygenation during cardiac surgery. $\mathrm{Br} J$ Anaesth. 2017:119(3):384-93.

34. Mohandas BS, Jagadeesh AM, Vikram SB. Impact of monitoring cerebral oxygen saturation on the outcome of patients undergoing open heart surgery. Ann Card Anaesth. 2013;16(2):102-6.

35. Serraino GF, Murphy GJ. Effects of cerebral near-infrared spectroscopy on the outcome of patients undergoing cardiac surgery: a systematic review of randomised trials. BMJ Open. 2017;7(9):e016613.

36. Ono M, Joshi B, Brady K, Easley RB, Zheng Y, Brown C, et al. Risks for impaired cerebral autoregulation during cardiopulmonary bypass and postoperative stroke. Br J Anaesth. 2012;109(3):391-8,

37. Joshi B, Brady K, Lee J, Easley B, Panigrahi R, Smielewski P, et al. Impaired autoregulation of cerebral blood flow during rewarming from hypothermic cardiopulmonary bypass and its potential association with stroke. Anesth Analg. 2010;110(2):321-8

\section{Publisher's Note}

Springer Nature remains neutral with regard to jurisdictional claims in published maps and institutional affiliations.

\section{Ready to submit your research? Choose BMC and benefit from}

- fast, convenient online submission

- thorough peer review by experienced researchers in your field

- rapid publication on acceptance

- support for research data, including large and complex data types

- gold Open Access which fosters wider collaboration and increased citations

- maximum visibility for your research: over $100 \mathrm{M}$ website views per year

At BMC, research is always in progress.

Learn more biomedcentral.com/submissions 